\title{
Effect of incentives on the financial attractiveness of solar industrial process heating in India ${ }^{\star}$
}

\author{
Ashish K. Sharma ${ }^{1, *}$, Chandan Sharma ${ }^{2}$, Subhash C. Mullick ${ }^{1}$, and Tara C. Kandpal ${ }^{1}$ \\ ${ }^{1}$ Center for Energy Studies, Indian Institute of Technology, Delhi, India \\ ${ }^{2}$ Mechanical Engineering Department, Government Engineering College, Ajmer, India
}

Received: 13 January 2017 / Received in final form: 8 July 2017 / Accepted: 27 July 2017

\begin{abstract}
India has a huge industrial demand for process heating at temperatures that can be provided with commercially available solar collectors. Government of India with support from multi-lateral agencies has initiated an ambitious programme for promoting large scale adoption of Solar Industrial Process Heating (SIPH) in the industrial sector of the country. This paper presents the details of an attempt to study the effect of several existing and potential incentives on the financial attractiveness of SIPH systems in India. A case of solar process heating in dairy industry has been presented to demonstrate the relative efficacy of different incentives on the economics of SIPH systems in terms of their impact on levelized cost of useful thermal energy delivered. Finally, policy implications of the results obtained have been discussed.
\end{abstract}

\section{Introduction}

Industrial process heating using solar energy is being considered as one of the alternatives for replacement of fossil fuels and ensuring sustainable solutions as it has the potential to address climate change concerns [1]. The efficiency of solar energy utilization for industrial process heating is expected to be more efficient as compared to the overall efficiency of solar thermal power plants[2]. However, as of now, Solar Industrial Process Heating (SIPH) contributes negligibly small share of the global process heating demand of the industrial sector [3]. Reasons for the same may include high initial capital investment requirement of SIPH systems (as compared to the current capital investment for a conventional process heating system), low price of fuels used for process heating, and inherent variability and intermittence of solar resource. A reduction in initial capital investment requirement of SIPH systems is expected with an increase in installed capacity of such systems, thus benefitting from economy of scale and learning. In order to promote the adoption of SIPH systems, in the initial phase, possibility of providing suitable incentives as well as policy support needs to be carefully investigated, particularly in emerging economies with large industrial sectors.

\footnotetext{
^ Paper presented at: World Renewable Energy Congress XVI, 59 February 2017, Murdoch University, Western Australia.

* e-mail: aksharmanith@gmail.com
}

To promote the harnessing of solar energy for industrial process heating, the Government of India has implemented a United Nation Development Project-Global Environmental Facility supported project [4]. The primary objective of the project is to promote and commercialize concentrating solar technologies for low and medium temperature process heating applications in India and also to reduce consequent greenhouse gas emissions. There are also provisions of incentives for promoting SIPH in the country and the same include capital subsidy, soft loan and accelerated depreciation, etc. In order to ensure efficiency and effectiveness in using public funds for incentivizing SIPH in the country it is necessary that the effect of different potential incentives on the financial attractiveness of SIPH systems be studied. Results of such an attempt to study and analyses the effect of some of the important incentives on levelized cost of useful thermal energy (LCUTE) delivered by solar process heating system in dairy industry in India is presented in this paper.

\subsection{Potential incentives for solar industrial process heating in India}

A brief description of three of the potential incentives for promoting SIPH in India is presented in the following paragraphs.

\subsubsection{Capital subsidy/viability gap funding}

Under the provision of capital subsidy, a certain fraction of the capital cost is shared by the Government. If the amount of capital subsidy is directly or indirectly linked with a certain target value of a parameter deciding the financial 
Table 1. Input parameters used for estimating the annual useful thermal energy delivered and corresponding LCUTE for SIPH system and LCUTE for conventional process heating system.

\begin{tabular}{|c|c|c|c|c|}
\hline Parameter & Symbol & Unit & Description & Reference $(\mathrm{s})$ \\
\hline \multicolumn{5}{|c|}{ (A) LCUTE of conventional process heating system } \\
\hline Capital cost & $C_{0}$ & Rs. & $7,000,000$ & - \\
\hline Useful life & $n$ & Years & 30 & {$[11,12]$} \\
\hline Calorific value of furnace oil & & $\mathrm{MJ} / \mathrm{kg}$ & 43.5 & \\
\hline $\begin{array}{l}\text { Efficiency of fuel utilization in the } \\
\text { boiler }\end{array}$ & - & $\%$ & 0.75 & \\
\hline Price of furnace oil (2016) & - & Rs. & 28 & {$[13]$} \\
\hline Discount rate & $d$ & $\%$ & 12 & \\
\hline \multicolumn{5}{|c|}{ (B) Parameters for estimating and LCUTE of solar industrial process heating system } \\
\hline Process heating requirement & $\mathrm{PHR}_{h}$ & GJ & 1.52 & - \\
\hline $\begin{array}{l}\text { Performance equation (parabolic } \\
\text { trough collector) }\end{array}$ & $\begin{array}{l}\eta=0.71-0.3581 * \\
(\mathrm{Tm}-\mathrm{Ta}) / I-0.0019 * \\
(\mathrm{Tm}-\mathrm{Ta})^{2} / I\end{array}$ & {$[14]$} & & \\
\hline Solar collection area & - & $\mathrm{m}^{2}$ & 942 & - \\
\hline $\begin{array}{l}\text { Cost of solar collector and } \\
\text { other components }\end{array}$ & - & Rs. $/ \mathrm{m}^{2}$ & $\begin{array}{l}26,500 \\
\text { (including } 18,000 / \mathrm{m}^{2} \\
\text { as solar collector cost) }\end{array}$ & {$[5]$} \\
\hline Thermal energy storage cost & - & Rs. & $2,993,188$ & - \\
\hline Capital cost of SIPH system & $C_{0}$ & Rs. & $27,956,188$ & - \\
\hline Useful life & $n$ & Years & 25 & {$[15]$} \\
\hline Annual operational cost & $\mathrm{ACO}$ & $\%$ & O & \\
\hline Annual maintenance cost & $\mathrm{ACM}$ & $\%$ & $1 \%$ of capital cost & \\
\hline $\begin{array}{l}\text { Annual escalation in operation and } \\
\text { maintenance cost }\end{array}$ & $£$ & $\%$ & $1 \%$ per year & \\
\hline Annual duration in performance & - & $\%$ & 0.005 & - \\
\hline Discount rate & $d$ & $\%$ & 12 & - \\
\hline
\end{tabular}

viability of the project, it is termed as the Viability Gap Funding (VGF). In India, the Ministry of New and Renewable Energy (MNRE), Government of India, has proposed to provide capital subsidy for SIPH systems with the amount of capital subsidy based on the benchmark cost of solar collectors up to a maximum of $70 \%$ of the project cost for some of the states in the country [4]. The fraction of capital subsidy depends on the state where the SIPH system has to be located or installed in the country [5].

\subsubsection{Soft loan}

Under this mechanism, a certain fraction of the capital cost is provided as loan at an interest rate that is lower than the commercial rate of interest prevailing in the market. It helps in lowering the cost of useful thermal energy delivered due to reduced periodic loan repayment installments. Such a provision has been made in the past for the promotion of wind power, solar home lighting systems, solar water heating systems and solar cookers solar thermal power generation in India [6-8]. For SIPH systems also soft loan is being provided by the Indian Renewable Energy Development Agency [9].

\subsubsection{Investment tax credit}

In order to encourage equity investors to invest in SIPH systems the provision of Investment Tax Credit (ITC) may be offered under which a certain fraction of the equity investment made is given as income tax credit. In such a case lower rates of return on equity are expected to be demanded by the equity investor. Alternatively, if the project developer of the SIPH systems can benefit from the ITC, the same would imply an effective reduction in the capital cost of the SIPH system.

In this study an attempt has been made to estimate the amount of VGF that needs to be provided to an SIPH system for dairy industry in India for the value of its levelized unit cost of thermal energy (LCUTE) matching with its target value decided on the basis of estimates corresponding to conventional process heating systems. Also the effect of soft loan, and ITCs and on LCUTE delivered by the SIPH system has also been studied. 


\section{Methodology}

To begin with, an SIPH system (with thermal storage) that can provide steam at 10.55 bar and $184^{\circ} \mathrm{C}$ with, mass flow rate of $600 \mathrm{~kg} / \mathrm{h}$ based on parabolic trough technology installed at the location of Anand in the state of Gujarat (annual direct normal irradiance value of $1837 \mathrm{kWh} / \mathrm{m}^{2}$ ) has been considered. Based on the process heating requirement, ambient conditions of the location and performance equation of solar collector (parabolic trough) used, the corresponding solar collection area requirement has been estimated. Further, using solar radiation data from Meteonorm[10], performance of SIPH system in terms of annual useful thermal energy delivered and solar fraction has been estimated. An annual useful thermal energy delivery of 3277 GJ has been estimated for this system at Anand, with an annual solar fraction of 0.25 . Details of SIPH system considered in the study are provided in Table 1.

\subsection{Estimation of levelized cost of useful thermal energy delivered}

In order to estimate the LCUTE delivered by the SIPH system, the values of unit cost of useful thermal energy (UCTE) delivered for each year of operation of the system were estimated separately as the output of the system may vary with time due to performance degradation (particularly for solar energy based system) and the annual cost of operation and maintenance of the system may also vary with time. The UCTE delivered by the process heating system for $j$ th year $\left(\mathrm{UCTE}_{j}\right)$ can be estimated as the ratio of total annual cost of the system in the $j$ th year $\left(\mathrm{TAC}_{j}\right)$ to the annual amount of useful thermal energy delivered by the system in that year. The total annual cost of the SIPH system in the $j$ th year $\left(\mathrm{TAC}_{j}\right)$ includes the equivalent annualized value of the capital cost (ACC) of the system, cost of operation (including the cost of fuel used during the year, if any), cost of maintenance and cost of insurance and rental, etc.

The equivalent $\mathrm{ACC}$ can be determined as

$$
\mathrm{ACC}=C_{0}\left[\frac{d(1+d)^{n}}{(1+d)^{n}-1}\right],
$$

with $d$ representing the discount rate applicable for the investment, $n$ the useful life of the system and $C_{0}$ the capital cost of SIPH system.

Thus the UCTE delivered for $j$ th year $\left(\mathrm{UCTE}_{j}\right)$ can be determined as

$$
\mathrm{UCTE}_{j}=\frac{\mathrm{ACC}+\mathrm{ACO}_{j}+\mathrm{ACM}_{j}}{\mathrm{AUTED}_{j}},
$$

where $\mathrm{ACO}_{j}$ represents the annual cost of operation in the $j$ th year, $\mathrm{ACM}_{j}$ the annual cost of maintenance during $j$ th year, and $\mathrm{AUTED}_{j}$ the annual amount of useful thermal energy delivered by the plant in $j$ th year.

$$
\mathrm{LCUTE}=\left[\sum_{j}^{n} \frac{\mathrm{UCTE}_{j}}{(1+d)^{j}}\right]\left[\frac{d(1+d)^{n}}{(1+d)^{n}-1}\right] .
$$

Table 2. VGF required (as a fraction of capital cost for different values of (LCUTE).

\begin{tabular}{ll}
\hline $\begin{array}{l}\text { Target value } \\
\text { of LCUTE for SIPH } \\
\text { system (Rs./GJ) }\end{array}$ & $\begin{array}{l}\text { Fraction of capital } \\
\text { cost required as } \\
\text { VGF }\left(f_{\text {vgf }}\right)\end{array}$ \\
\hline 650 & 0.505 \\
700 & 0.460 \\
750 & 0.420 \\
800 & 0.374 \\
850 & 0.330 \\
900 & 0.285 \\
924 & 0.264 \\
950 & 0.245 \\
1000 & 0.195 \\
\hline
\end{tabular}

The above approach for estimating the LCUTE essentially determines the cumulative present values of the $\mathrm{UCTE}_{j}$ for all years during the useful life of the project and then redistributes the same uniformly over the useful time.

Annual useful energy delivered by the conventional process heating system in $j$ th year is estimated as (assuming $100 \%$ capacity utilization).

$$
\operatorname{AUTED}_{j}=\left(\mathrm{PHR}_{h}\right) \times(365) \times(24),
$$

with $\mathrm{PHR}_{h}$ representing the hourly process heating requirement. While estimating annual cost of operation of $j$ th year $\left(\mathrm{AC}_{j}\right)$ only the cost of fuel utilized (furnace oil) in the boiler during the year has been internalized.

Using the benchmark cost of solar collectors (parabolic trough) as provided by MNRE, and the input parameters presented in Table 1, estimates for LCUTE for SIPH and conventional process heating system have been obtained. The value of LCUTE for annual useful thermal energy delivery of 3277 GJ at the location of Anand in Gujarat has been estimated at Rs. 1221 per GJ (referred to as base case LCUTE of SIPH system in this paper). On the other hand, LCUTE of conventional process heating system using furnace oil as fuel has been estimated at Rs. 924 per GJ (without considering any possible escalation in the price of furnace oil in future).

\subsection{Estimation of the required amount of viability gap funding}

The provision of VGF provided (a fraction $f_{\mathrm{vgf}}$ of capital cost $\left(C_{0}\right)$ will essentially reduce the effective capital cost of the SIPH system and thus the value of the LCUTE delivered. The effective capital cost after provision of VGF will be $C_{0}\left(1-f_{\mathrm{vgf}}\right)$. In the present study, to attain the target values of LCUTE, fraction of capital cost that may require as $\operatorname{VGF}\left(f_{\mathrm{vgf}}\right)$ has been estimated.

\subsection{Soft loan}

To analyses the effect of soft loan on the LCUTE for solar industrial process heating systems it is assumed that the system is financed with a debt to equity ratio of $75: 25$ and the 
Table 3. Effect of rate of interest on loan on the levelized cost of useful thermal energy (LCUTE).

\begin{tabular}{llll}
\hline $\begin{array}{l}\text { Rate of interest } \\
\left(I_{d}\right) \text { on loan }\end{array}$ & $\begin{array}{l}\text { Rate of return } \\
\left(R_{e}\right) \text { on equity } \\
(25 \% \text { share of } \\
\text { capital cost) }(\%)\end{array}$ & $\begin{array}{l}\text { Weighted average } \\
\text { cost of capital }(\%)\end{array}$ & $\begin{array}{l}\text { LCUTE of SIPH } \\
\text { system } \\
\text { (Rs. } / \text { GJ) }\end{array}$ \\
\hline 8.0 & 15 & & 1054 \\
7.5 & 15 & 9.8 & 1027 \\
7.0 & 15 & 9.4 & 1000 \\
6.5 & 15 & 9.0 & 974 \\
6.0 & 15 & 8.6 & 948 \\
5.5 & 15 & 8.3 & 896 \\
5.0 & 15 & 7.9 & 922 \\
4.5 & 15 & 7.5 & 871 \\
4.0 & 15 & 7.1 & 846 \\
\hline
\end{tabular}

Table 4. LCUTE at different rate of ITC.

\begin{tabular}{ll}
\hline $\begin{array}{l}\text { Return on investment } \\
\text { tax credits }\left(R_{\mathrm{ITC}}\right)(\%)\end{array}$ & $\begin{array}{l}\text { LCUTE of SIPH } \\
\text { system }(\text { Rs. } / \mathrm{GJ})\end{array}$ \\
\hline 10 & 1120 \\
15 & 1020 \\
20 & 1070 \\
25 & 969 \\
30 & 919 \\
35 & 869 \\
40 & 819 \\
\hline
\end{tabular}

expected annual rate of return on the equity component is $15 \%$. The annual interest rate on the debt component is then varied between $4 \%$ and $8 \%$ to simulate various possible values of interest rate on soft loan. In each case, the weighted average cost of capital (WACC) is determined to be used as the discount rate for determination of LCUTE. The WACC is estimated as:

$$
\mathrm{WACC}=\left(I_{d} f_{d}\right) \times\left(R_{e} f_{e}\right),
$$

where $I_{d}$ represents the rate of interest on debt component, $f_{d}$, the fraction of debt component, $R_{e}$, the expected rate of return on equity component and $f_{e}$, the fraction of equity in financing the system.

\subsection{Investment tax credit}

In the present study it is assumed that the ITC accrues to the project developer during the first year (with the end of the period convention followed for all cash flows). The effective value of the capital cost of the SIPH system with the provision of ITC at a rate of $R_{\mathrm{ITC}}$ can be calculated as

$$
\text { Effective capital cost }=\left[C_{0}-\frac{C_{0} R_{\mathrm{ITC}}}{(1+d)}\right] .
$$

Using the effective capital cost as determined from equation (6), the LCUTE is calculated. In the present study the value of $R_{\mathrm{ITC}}$ is assumed to vary between $10 \%$ and $40 \%$.

\section{Results and discussion}

The mathematical frameworks presented in Section 3 have been used to estimate the amount of VGF as well as to analyze the effect of soft loan and ITC on the levelized UCTE delivered by a solar industrial process heating system in dairy industry in India. A summary of the results obtained is presented in the following paragraphs.

\subsection{Estimates for viability gap funding}

The values for the fraction of capital cost that is required as VGF to attain different target values of LCUTE delivery of solar industrial process heating system in dairy industry in India are presented in Table 2.

It may be noted that to attain an LCUTE value of Rs. 924 per GJ for the SIPH system (i.e. to match the LCUTE for the conventional furnace oil fired process heating system) about $26 \%$ of the capital cost needs to be provided as VGF for the system. As expected, for achieving even lower values of LCUTE, the extent of VGF would increase.

\subsection{Effect of soft loan on levelized unit cost of useful thermal energy delivered}

Table 3 presents the effect of soft loan on the LCUTE delivered by the SIPH system. Within interest rate of (4-8\% and expected return on equity of $15 \%$, a significant reduction in the LCUTE delivery of SIPH systems (Rs. 1054-846) has been observed. Results indicate that, for interest rates up to $6 \%$ LCUTE delivered by the SIPH system may become comparable with LCUTE value for the conventional process heating system. For the case considered in this study, the extent of soft loan at which estimated value of LCUTE (Rs. 1221 per GJ) of solar based process heating in dairy industry in India match with the LCUTE (Rs. 924 per GJ) of conventional process heating system is estimated at $5.6 \%$. 


\subsection{Effect of investment tax credit on the levelized cost of useful thermal energy delivery}

Following the methodology described in Section 2.4, at different values for the rate of ITC, levelized UCTE delivery for the SIPH system has been estimated and results are presented in Table 4 . It may be noted that, so to make solar industrial process heating comparable with the conventional process heating, ITC between $25 \%$ and $35 \%$ should be provided to the project developer. For example, to achieve a value of Rs. 924 per GJ for the LCUTE an ITC at a rate of $29.5 \%$ would be needed.

\section{Concluding remarks}

Levelized UCTE delivery of solar industrial process heating system in dairy industry in India has been estimated. It has been observed that, levelized cost of useful energy delivered by the solar industrial process heating system (Rs. 1212 per GJ) is relatively higher than the levelized UCTE (Rs. 964 per GJ) delivered by the conventional process heating system. Therefore, to make SIPH economically attractive certain incentives such as VGF, soft loan ITC could be provided.

The provision of about $30 \%$ of the capital cost of the SIPH system as VGF can make levelized UCTE delivery comparable with the LCUTE delivery of conventional process heating system. On the other hand, if incentive is provided as a soft loan than to achieve the target values of LCUTE delivery rate of interest approximately at $6 \%$ on the debt component is required. Similarly a provision of ITC at a rate of approximately $30 \%$ could also make the SIPH system in dairy industry competitive with commercially available options for process heating.

Financial support provided to the first author (Ashish Kumar Sharma) under the International Travel Scheme provided by the Science and Engineering Research Board, Department of Science and Technology, Government of India to present the paper in the World Renewable EnergyCongress-2017 to be held in Perth is gratefully acknowledged.

\section{References}

1. A.K. Sharma et al., Potential of solar industrial process heating in dairy industry in India and consequent carbon mitigation, J. Clean Prod. 140, 714 (2017)

2. S.A. Kalogirou, Solar thermal collectors and applications, Progr. Energy Combust. Sci. 30, 231 (2004)

3. IRENA, Solar Heat for Industrial Processes - Technology Brief (International Renewable Energy Agency, 2016)

4. UNDP, UNEP-GEF Project-Market Development \& Promotion of Solar Concentrator based process heat applications in India (2011)

5. Sun Focus, A quarterly magazine on concentrated solar heat. India's quest for Solar Steam and Process Heat (2016)

6. IREDA, Indian Renewable Energy Development Agency, Government of India (2013)

7. MNRE, Ministry of New and Renewable Energy, Government of India, Annual Report (2013)

8. C. Sharma et al., Solar thermal power generation in India: effect of potential incentives on unit cost of electricity, Int. J. Sustain. Energy 36, 722 (2015)

9. IREDA, Loan Scheme to Promote the Concentrating Solar Thermal Projects in India (Indian Renewable Energy Development Agency, Government of India, 2016)

10. Meteonorm, Irradiation data for every place on earth (2014)

11. CEA, Data on Data on Petroleum Fuels used in various Gas Turbines 8 Diesel Engine Power Plants in the Country during 2003-04 (Central Electricity Authority, 2005)

12. UNEP, Fuel and Combustion. Energy Efficiency Guide for Industry in Asia (United Nations Environment Programme, Nairobi, Kenya, 2006)

13. MP\&NG, Indian Petroleum and Natural Gas Statistics (Ministry of Petroleum \& Natural Gas, Government of India, 2016)

14. SRCC, Solar Rating and Certification Corporation. Certified solar collector. Tubular type. Certification number 10001929 (2014)

15. CSH, Concentrated Solar Heat, Case Studies (2016)

Cite this article as: Ashish K. Sharma, Chandan Sharma, Subhash C. Mullick, Tara C. Kandpal, Effect of incentives on the financial attractiveness of solar industrial process heating in India, Renew. Energy Environ. Sustain. 2, 33 (2017) 